had a patient with acute glaucoma referred from a physician, who had used a solution of atropin for the intolerable pain, thinking he was dealing with a case of iritis. The vain soon subsided, vision was reduced to fingers, but gradually rose to $3 / 50$. When an operation was suggested the patient dropped out.

Intraocular tumors produce secondary glaucoma by causing incrcased pressure in the vitreous, while posterior synechice, anterior staphyloma from injuries, dislocation of the lens, and serous cyclitis obstruct the outlets of the eye, the latter clogging the filtration angle with albuminous fiuid.

Sala found an excess of albumin in the aqueous humor in two cases of contusion of the eyeball, followed by glaucoma. ${ }^{7}$ Peters $^{8}$ corroborated this by citing four cases of glaucoma after contusion, with the aqueous loaded with albumin. He suggested that the traumatism caused paralysis of the ciliary body and consequently an increased secretion of albumin, impeding filtration.

Bartels ${ }^{9}$ incised the conjunctiva in four or five places in rabbits and dogs, passing threads behind the muscles from one slit to the next and tying the threads. He produced a condition similar to acute glaucoma, injection of the conjunctiva, anesthetic cornea, wide pupils (except in rabbits), and increased tension. There was absence of obstruction in the filtration angle in all cases. $\mathrm{He}$ concluded that obstruction in the anterior ciliary venous circulation is the probable cause of glaucoma.

According to Priestley Smith, ${ }^{10}$ the lens increases in diameter onc-tenth and in volume one-third between the ages of 20 and 60 . He holds that hyperopic eyes are most liable to the discase, for in these the lens develops ont of proportion to the dimensions of the eye, pressing against the filtration angle. He claims also that a narrow cornen goes with a small eye; and in patients whose corneal diameter is not more than $10 \mathrm{~mm}$., few escape the disease.

I examined the cyes of 200 persons of all ages to see to what extent the lens encroached on the ciliary processes as age advanced. I applied the Würdemann lamp to the margins of the lids at the outer canthus and looked obliquely through the pupil. When one eye is affected with glaucoma, the other may be examined by using alypin for a local anesthetic, as it does not increase the tension of the eye, but rather decreases it. If the observer looks forward far enough into the normal eve, he sees the ciliary body as a dark ring."11

The space between the rounded margin of the lens and the ciliary processes is given as 0.5 to $0.6 \mathrm{~mm}$. The lens being about $9 \mathrm{~mm}$. in diameter, if this diameter were increased one-tenth, it would come near to the ciliary processes; then any unusual congestion might cause trouble.

An eye affected by glaucoma has a narrow circumlental space, as a matter of course. It is also narrow in all cases in which, after middle age, the lens is pushed forward so far as to render the anterior chamber shallow. This condition is common with people who die of old age and who never had glaucoma. Since commencing this line of investigation. I have noticed many cases in which the anterior chamber was very shallow, and the

7. Glaucoma Following Discission and Contusions of the Eyeball, Klin. Monatsb. f. Augenh., April, 1904.

8. Glaucoma After Contusions of the Eye and Its Treatment, K!in. Monatsb. f. Augenh., Dec., 1904.

9. Ueber Blutgefaisse des Auges bet Glaukom, und ueber experlmentelles glaukom durch Versperrung von vorderen Abgefïhrenden Blutbahnen, Berlin, S. Karger, 95.

10. Norris and Ollver's System, fll, 650.

11. Wiirdemann (I. V.) : Opbth. Rec., November, 1906. circumlental space also, yet there was no increase of tension. I have noticed also that the members of a family in which glaucoma has appeared all have a narrow circumlental space. I have not seen a case of narrow cornea, all the cases of glaucoma that I have seen having corneas measuring $11.5 \mathrm{~mm}$. Hypcropia is common, but some cases are emmetropes.

Priestley Smith, with scientific fairness, remarks, ${ }^{12}$ "the obstruction at the outlet, discoverable in eyes blinded by glaucoma, explains the excess of pressure in the chambers, but it does not reveal the starting point of the disease." He describes an apparatus for injecting the eye, ${ }^{13}$ consisting of two flexible tubes, each being provided with a pinch tap, and ending in hollow needles. These tubes are suspended at the same height. The eyes of a sheep are removed immediately after death and injected while they are still warm. One of the needles is inserted into the aqueous chamber, and the other into the vitrcous chamber. The fluid in the tubes is a 1 per cent. solution of anilin black. When the tubes are at the same height, the fluid passes through the filtration angle, and flows from the cut ends of the cpiscleral veins. Now, if the tube connected with the vitreous chamber is elevated ahove the other, the process of filtration stops; the lens and iris advance, and there is no escape of fluid from the severed veins.

It would seem that chronic glaucoma must be caused by excessive pressure in the vitreous chamber, caused by diseased blood ressels in the uveal tract; at the same time there is probable alteration in the constitution of the aqueous humor, which blocks up the outlets. We have seen that this alteration in the fluids produces glaucoma after trammatism, and in serous crelitis ; and Troncoso claims to have found an excess of albumin in eves affected by chronic glaucoma. Why mav not the ciliary process scercte albumin when age has changed the character of the blood vessels?

If sympathectomy ever relieved the intraocular tension, it dir it through its influence on the circulation in the chorioid and the ciliary processes. The same must be said of iridectomy. It does not reduce the tension immediately, showing that its influence is exerted on the intraocular circulation. Another thing pointing in the same direction is the fact that in some cases of iridochorioiditis with diminished tension, it is increased by an iridectomy. ${ }^{\mathbf{1 4}}$

My thanks are due to Dr. Myles Standish, Dr. H. B. Chandler and their assistant, Dr. Clap, in the Fye and Ear Infirmary, for their courtesy in allowing me to examine their patients.

\section{THE SURGICAL TREATMENT OF CHRONIC GLAUCOMA.*}

\section{S. D. RISLEY, A.M., M.D., PII.D. PHILADELPHIA.}

There is probably no form of ocular disease which has excited more interest or which affords, in some of its clinical features, more reasonable opportunity for opposing opinions than chronic glaucoma.

Although it is my purpose in this paper to discuss the surgical treatment of the disease, it is, first of all, impor-

\section{Norris and Oliver's System, iil, 633}

13. Ibid., 632 .

14. Berry (George) : Diseases of the Eye, Art. Glaucoma.

* Read in the Section on Ophthalmology of the American Medi. cal Association at the Fifty-eighth Annual Session, held at At lantle City, June, 1907 
tant that we should entertain a common understanding of the clinical picture had in mind.

For a generation there has been no doubt in the minds of experienced surgeons as to the necessity and signal value of iridectomy in the treatment of the inflammatory types of glaucoma. But in so-called chronic, simple, or non-inflammatory glaucoma there has been much diversity of opinion as to the value of surgical interference.

It is probable that the adverse views which have been and are still entertained by different surgeons depend, in large measure, on the mental concept entertained by the individual surgeon of both the nature of the disease and the exact clinical picture had under consideration.

It can not be denied that there is room for doubt as to the exact nature of certain comparatively rare cases of ncular disease characterized by steadily increasing impairment of vision, a concentric narrowing of the field, and typical glaucomatous cupping of the optic nerve, but with entire absence of pain, inflammatory signs, demonstrable increase of tension in the globe or notable exacerbations in the clinical history. The progress in this group of cases is steadily onward toward blindness, much as in simple atrophy, unless it is possible by treatment to arrest its course.

There is a wide reach between this picture of glaucoma simplex and, for example, the stormy manifestations of disease afforded by glaucoma fulminans, with its violent objective and subjective signs of inflammation, the stony hard ball and almost sudden abrogation of functioning power. Between these extremes, however, lies the large group of cases with which we are all familiar and which I believe to be those our chairman wishes me to discuss. A careful study of this group, however, will serve to show that at some time in their early history these patients have manifested the symptoms of disease so vaguely as to leave both patient and surgeon in doubt: The former as to whether anything is actually wrong with his eyes, whether he is not, after all, the victim of his imagination; the latter in doubt, certainly as to the nature, perhaps even of the existence, of a disease of which he now and again gets vague glimpses only, but which for many weeks or months, it may be, eludes his most subtle means of analysis and leaves his diagnosis suspended until such time as the cupping nerve, the contracting field, the increasing impairment of central vision shall have declared its nature. In a word, till the condition has passed from the stage of incipient glaucoma simplex into the stage of easily recognized chronic glaucoma.

The question for the surgeon to answer to his own satisfaction is: Does this subtle, but colorless, progressive malady belong in the same category with inflammatory glaucoma? The answer given to this inquiry will, in great measure, determine both the course and vigor of his advice and treatment.

Our unwillingness to answer it definitely in the affirmative is the cause of the vague and variable condition of the literature of chronic glaucoma and affords sufficient reason for the timid and vacillating treatment of the disease during its early stage. That the affirmative answer is too often, or too long, withheld in individual cases should not cause surprise. The indeterminate clinical history, in a relatively small group of cases, is maintained to the end ; that is to sav, until irretrievable blindness has resulted before the inflammatory stage of the disease is reached. Then, sooner or later, come the engorged long anterior ciliary vessels, the hard eyeball. the completely atrophic, deeply cupped nerve, and pain, with more or less well-pronounced inflammatory signs.

Fortunately, however, in many cases new and more determinate features are added to the clinical progress of the disease which prompt the timid surgeon to defnite action before it is too late. These symptoms are generally slight, transient exacerbations of increased dimness of vision, with suggestion of discomfort or actual pain, accompanied with a sense of fulness in the eye and periorbital region supervene.

The patient may ascribe the symptoms to overfatigue after a hard day, to some error in diet, to overuse of the eyes or to dim or too bright light. After rest the acute symptoms disappear and may not recur for many weeks or even months, but the impression has been left on the mind of the patient that the eyes are not so good as they were before the attack of dimness. Recurrences, however, are sure to follow and they come with increasing frequency and variable severity. The recovery after each exacerbation is not so complete as at first. The impairment of vision soon becomes permanent even between the attacks, but worse during their continuance, and pain becomes a well-marked feature. Halos are observed around the gas flame or lamp, and the eyes are injected, it may be but slightly. The cornea is steamy, the tension of the ball is increased eren between attacks, but is variable, being greater during the recurring more acute exacerbations at which time the sensibility of the cornea is diminished. If no treatment is instituted this history may be pursued for long periods of time, finally causing complete loss of vision with atrophy and characteristic cupping of the nerve. In other cases following on some unusual stress, as ill fortune, or some cause for grief, the scene closes with a sudden attack of glaucoma fulminans.

The dangers which cluster thickly about the clinical history of chronic glaucoma are greatly enhanced by this subtle beginning and the variable and treacherous course of the disease which has been briefly describer. There is no form of ocular disease in which early recognition and well-defined views as to its nature and treatment are more important; for, if treatment is delayed until the delicate retinal fibers, where they emerge over the scleral ring, are injured too greatly by the recurring periods of increased tension of the globe, it is not to be expected that any procedure whatever can restore their function.

The greatest danger of delay on the part of the surgeon is in the group of patients in whom the disease progresses without obvious exacerbations; that is to say. in cases in which there has been demonstrable hardness of the ball or attacks of extraordinary dimness of sight. Here the inquiry may reasonably be made, Why operate, or, for that matter, why use miotics, in an eye in which increase of tension has never been observed, sine both the miotics and iridectomy are employed with the ostensible design of reducing increased tension?

In reply it may be observed that increased tension of the eyeball is always relative. In the tirst place, it is probable that our mental concept of normal tension is an overestimate for many eyes. That is to say, for some eyes, e. g., those with a thin sclera, a degree of resistance to palpation which would be normal for many eyes is excessive and amounts to an increased hardness, sufficient, indeed, to account for the cupped nerve. For it is fair to assume that in the eye with a thin sclerotic coat there will be also a relatively too readily yielding lamina cribrosa.

Then, too, it is not only possible but it is rendered 
probable by certain clinical signs that mild exacerbations of increased tension coming on especially in the night often pass without recognition by the patient. Many persons ascribe their insomnia to ocular discomfort, and this symptom is frequently ameliorated by the use of weak solutions of eserin salicylate instilled at bedtime. The same drug will often relieve also the weak eyes and nccipital pains with which many patients awake early in the morning.

There is, moreover, a rational basis for this, in some measure, a priori reasoning. The patient retires for sleep after the fatigues of the day and assumes a recumbent posture. The lights are extinguished and the pupils dilate, blocking the spaces of Fontana as effectually as though a mydriatic had been employed, thus furnishing conditions which delay excretion of the intraocular fluids and favor increase of tension in the globe.

That this deductive reasoning is based on a correct premise seems to find corroboration in the well-known frequency with which attacks of acute, inflammatory glaucoma come on in the night, during sleep, in patients with glaucoma imminens. We are justified, therefore, in assuming that in cases of marked cupping of the nerve without any increase of tension ever having been observed, that it had nevertheless occurred, possibly in the night or during sleep, an inference which finds additional force in the observed clinical fact of the wellknown relation. under all ordinary circumstances, between the cupped nerve. contracted field of vision and increased tension of the ball.

It is believed that the suggestions in the preceding pages will find corroboration in the following clinical histories of carefully observed cases occurring in my private practice, in all of which opportunity was afforded for continuous observation for long periods of time. After careful consideration this course was chosen in preference to carefully applied statistical tables of large numbers of both private and clinic patients, in many of which the clinical history was incomplete.

CASE 1.-Chronic Glaucoma in Right Eye. Iridectomy, followed by Creeping Non-inflammatory Glaucoma in the left, Culminating in an Attack of Acute Inflammatory Glaucoma and Permanent Loss of Vision.

Patient.-Mrs. M., aged 50, was sent to me by her physician in 1879 for failing vision in the right eye. She had been treated several months for recurring right hemicrania, which had been regarded by her physician as the cause of the pain and loss of sight in the right eye. The eyeball was hard, pupil dilated, cornea slightly hazy. and lacking in sensibility. Vision was reduced to one-fourth or less, $20 / \mathrm{lxxx}$, and the field to a small area in the temple side. The nerve was deeply cupped and atrophic. The left eye was aparently normal in all respects. $\mathrm{V} .=20 / \mathrm{xx}$.

operation.-A broad upward iridectomy was performed on the right eye which gave rapid and complete relief from pain, and vision rose to $20 / \mathrm{lxiv}$, with normal tension of the globe and some improvement in the field.

Postoperative History.-There was no recurrence of the glatcoma and vision was maintained for two years, then slowly sank through atrophy of the optic nerve until total blindness was reached in 1884, five years after her first consultation. In October, 1883, she was alarmed over a spell of dim sight in the left eye while at her dressing table preparing for an evening entertainment, and she came to see me the following morning. The impaired vision lasted less than ten minutes, she thought, but she then related that the trouble in her right eye began in the same manner several years before I had seen her, and was repeated at varying intervals until it had culminated in the "neuralgie" attacks in the eye, which both she and her phy. sician believed were caused by the hemicrania; she declared that she now knew better, and begged that something be done to arrest the disease in the left eye.
Treatment.-The vision was $20 / \mathrm{xx}$; there was no contraction of the field and tension was normal. She received eserin solution to be used in the event of another attack, which unfortunately followed the first in a few weeks, coming on in the even. ing again after a fatiguing day in the shops. These attacks continued to occur at long but varying intervals for a year and a half, but were relieved in a few moments by the instillation of the eserin solution, which she kept constantly at hand. The exacerbations occurred invariably in the evening, but had always disappeared before she could get to my office for study, so that up to this time I had not, seen her during an attack.

April 10, 1884: V. $=20 / \mathrm{xx}$, and there was but little if any variation from the normal in the field of vision, but there was a quite obvious cupping of the nerve at the lower border. The lower temporal portion of the nerve was gray. She was then told of the undoubted character of the disease and that it would surely pursue a similar history to that of the right eye, and was urged to consider the necessity for operation in the near future. The fate of the neglected right eye, so far from convincing her of the wisdom of early interference, as it should have done, had the directly opposite effect on her mind.

Jan. 24, 1889: I did not see her again until this date, nearly five years later. In the meantime, however, she had continued to use the eserin solution with increasing frequency on her own responsibility, until its daily use had become a constant habit. She had, as a result, a chronic granular conjunctivitis. $\mathrm{V} .=20 / \mathrm{xl}$. The field of vision was contracted, nearly concentrically, to about $30^{\circ}$ on the perimeter chart, with an additional cut in the lower nasal field. The cornea was clear, the pupil reacted, but somewhat sluggishly, to light and shade and contracted under a miotic. The anterior chamber was shallow, tension doubtfully +1 . The nucleus of the lens was gray and ophthalmoscopic examination difficult. Operation was then strongly urged but declined. She received a stronger solution of eserin salicylate to be used twice daily. Under this vision rose to $20 / \mathrm{xxx}$ and the field was broader.

May 22, 1889: Her visits had been discontinued for the previous five months, but the miotic was continued. Vision remained at $20 / x \times x$, and there was no notable change in the field, notwithstanding the fact that she had many attacks of transient impairment of vision, which she observed were apparently precipitated by eating fruits, especially peaches or grapes. She again declined to submit to iridectomy, and did not return until November, 1889, the miotic having been steadily employed. In the meantime her husband had suffered financial ruin and died. Her vision had sunk to $1 / 10$, the pupil was habitually dilated, but contracted under a strong solution of eserin; the field was so much contracted that she found difficulty in going about without an attendant, the lower half of the field of vision being entirely absent. The dilated pupil permitted a study of the nerve, which was now deeply cupped. She was having moderate pain. The ball was rigid but not very hard.

Nov. 28, 1889: While using the eserin solution three times daily she suffered a violent attack of acute inflammatory glaucoma, which came on in the night. The following morning the ball was stony hard; there was no perception of light. She was suffering intense pain and begged for immediate operation, which was performed under general anesthesia in the afternoon after a cautious paracentesis in the morning. On the third day she had conjunctival inflammation with ehemosis, which subsided under treatment. The pain and tension were entirely relieved, the wound healed kindly, but convalescence was tedious. Vision slowly returned.

Feb. 2, 1891: Fourteen months after iridectomy, V.= 20/exxvi. The lower field was blind, even for candle flame. Two months later vision was only $2 / \mathrm{cc}$, eccentric fixation, and sank rapidly to total blindness. She lived about two years subject to the most distressing visual hallucinations.

This unfortunate history can not be contemplated without sadness. There can be but little doubt, in the light of many other experiences, that blindness would have been prevented in both eyes of this patient har a skilful iridectomy been performed in each during the 
early stage of the disease. In the first eye the glaucoma was cured by the operation, but too late to avert blindness by progressive atrophy of the optic nerve. In the second eye she would not submit to operation until too late.

The history, however, seems to show the danger and futility of relying with too great confidence, certainly in all cases, on the sufficiency of miotics in averting the fatal denouement.

The following history of a patient who came under observation during the same years as the previous case seems to justify the conclusions just formulated.

CASE 2.-Chronic Glaucoma, Exacerbations of Subacute Inflammatory Glaucoma, Following Many Years of Recurring Attacks of Dim Vision without Pain or Redness of the Fye.

Patient.-Mrs. T., aged 40, consulted me in November, 1887, with chronic glaucoma. She related that she had consulted two eminent colleagues, the first in $\mathbf{1 8 7 5}$, the second in 1876 , both of whom had advised iridectomy, to which she had not submitted. Her vision had been failing steadily for a long time before consulting them, but she had frequent attacks of dim sight, lasting at times for a few minutes only, but often for several hours. These attacks had not been acompanied by pain or redness until 1878. The tension was, in the right eye, $+1 . V .=20 /$ lxx. The pupil showed a tendency to dilate, there was a well-marked glaucomatous cup and an intermittent pulsation of the lower temporal retinal artery. Left eye, $\mathrm{V} .=$ q. p. 1. T. +2 , pupil dilated, deep glaucomatous cup and retinal pulse. Some ciliary injection and pain.

Operation.--Iridectomy was performed under general anes. thesia in both eyes, with an interval of one week. The symptoms were entirely relieved, the fields of vision improved in both eyes and vision had improved on July 10, 1879, eight months after the operation, in $O$. D., with correcting glasses, to $20 /$ lxiv; in O. S. to $20 / \mathrm{cc}$. Eleven years later vision in the right eye was $20 / \mathrm{xxx}$, but in the left there was nearly complete blindness, with a total atrophy of the nerve. In Oetober, 1906 , I saw this patient, then 68 years of age, alight from a railroad train and pursue her way unattended, evidently seeing her way about with ease.

Case 3.-Non-inflammatory Glaucoma in both liyes, Progressive Loss of Vision and Contraction of Field, Deep Glaucomatous Cupping of Both Nerves. No History of Exacerbations; Constant Headache; Iridectomy in Both Fyes at One Sitling.

Patient.-Mary F., aged 24 , a mulatto, came to see me in 1878 because of rapidly failing vision and constant headache. There had been no inflammatory symptoms at any time and no exacerbations of ocular disturbance, with the sole exception of increased pain in the head from time to time, which radiated from the eyes and periorbital region to occiput, often keeping her awake at night. The failure of vision had been rapid until she at last found difficulty in doing work about the house. She stumbled over chairs, knocked things over on table and mantelpiece, etc. This proved to be due to marked contraction of the field of vision, which at no point was wider than $40^{\circ}$, and was only $10^{\circ}$ in the upper and lower fields of each eye. Central vision was $20 / \mathrm{xI}$ in each, and tension was normal. Both optic nerves were gray, devoid of capillaries and deeply cupped.

Operation.--She was admitted to the Episcopal Hospital and a broad upward iridectomy performed on both eyes at the same sitting, under general anesthesia, on June 7, 1878. The convalescence was uneventful, and on July 23, 1878, with correcting glasses, central rision remained at $20 / x l$, but the field was wider.

Postoperative History.-This patient was kept under observation for many years. She married and gave birth to several healthy children. She was last seen at the Wills Eye Hospital, March 16, 1894, sixteen years after the iridectomies were performed. She still had high grade of astigmatism in both eyes, but with careful correction O. D. V. $=6 /$ vi, O. S. V. $=6 /$ ix, miscalling confusion letters with each eye. The field of vision in the right eye, temple $76^{\circ}$, nasal $10^{\circ}$, lower temple $55^{\circ}$, lower nasal quadrant blind, upper temple $40^{\circ}$. In the left eye, temple feld $76^{\circ}$. lower and upper temple quadrants $40^{\circ}$, upper nasal $10^{\circ}$, lower nasal $50^{\circ}$.
'This patient, who at 24 years of age presented all the classical signs of advancing glaucoma simplex, i. e., absence of increased tension or inflammation, but with characteristically cupped nerves and contracted fields, sixteen years later was found with a permanent improvement in both central and peripheral vision and without any advance in the atrophy of the nerves.

CASE 4.-Myopic Astigmatism.

Patient.-Mrs. McC., aged 30, was referred to me by Dr. George M. Gould in June, 1897. She had for many months been using eserin under Dr. Gould's advice.

History.-There was a deep glaucomatous cup in both nerves and marked contraction of the field of vision in the right eye, to $30^{\circ}$ in the temple and lower, $20^{\circ}$ above and to $10^{\circ}$ in the nasal field. The increase of tension was apparently slight, but the balls were large and the sclera thin. There was a broad, atrophic, myopic conus at the temporal side of both optic nerves. In the right eye, with correcting glass $\mathrm{V} .=20 / \mathrm{c}(1 / 5)$. The left eye had only quantitative perception of light, $\mathbf{T} .=+$ 1. She was suffering from violent periorbital and occipital headaches, was extremely nervous and hysterical, and was a victim of vaginismus, which had been the cause of much do. mestic discord. There had never been inflammatory symptoms or exacerbations of ocular disturbance.

Operation.- She was admitted to the Wills Eye Hospital and a broad, peripheral iridectomy was performed on both eyes. The periorbital and occipital pain promptly disappeared and the field of vision in the right eye markedly improved in all directions. The left eye resumed normal tension and was free from pain, but remained blind.

Postoperative History.-Nine years later this patient returned with an acute conjunctivitis. There had been no return of glaucoma, and the acuity of central vision remained as in 1897 , so that she was able to earn a living for herself and three children as a music teacher.

It is interesting to note that, after the relief from her simple glaucoma by operation, her general neurotic condition had greatly improved and she had given birth to three children.

It is obvious that the iridectomy had saved the right eye from the fateful dénouement of the simple glaucoma which had befallen the left under the steady use of the miotics alone.

CAsE 5.-Chronic Non-inflammatory Glancoma, Entire Absence of Pain or Tension. Iridectomy in Both Fyes.

Patient.-Mrs. K., aged 77 , a tall, spare, swarthy woman with stalwart frame, was brought to me in March, 1895, by Dr. S. W. Wiley, of Norristown, Pa., complaining only of her failing vision, supposing it to be due to eataract. The vision had not been cood for many years, but failure had been more rapid during the last year.

Examination-O. D. H. $=3$. D., with correcting glass. $\mathrm{V} .=1 / \mathrm{lx}$, and nasal field cut to fxation point, temple $50^{\circ}, 30^{\circ}$ above and below. The pupil reacted sluggishly, the tension was doubtfully increased, but the eyeball was rigid. The media were clear. The nerve was grecnish and deeply cupped to its scleral border, except at the nasal side, where the vessels emerged in a peculiar manner from the apex of a decp physiologic excavation. There was a slow, ocensional pulse wave in the lower temporal artery. In $O$. S. with her correcting glass +4 D. V. $=6 /$ xriii. Field cut to near the fixation point on nasal side, but temple ficld nearly normal. $\mathrm{T} .=+$ ? Pupil reacted to light and contracted under eserin promptly. The nerve was cupped as in $O$. D., but was obviously less atrophic. Iridectomy was advised in both eyes as the only means of arresting the disease, but an unfavorable prognosis was given. She received a solution of eserin to be used as freely as possible without causing pain, and returned to her home in the center of the state. She returned after two weeks with marked improvement in central vision in both eyes, but a more pronounced cut in the lower field of each.

Operation.-A broad peripheral iridectomy was performed on the left eye and six days later on the right. Recovery was rapid in each and uneventful. 
Postoperative Histury.-A pril 18, 1895: The tension was subnormal in both eyes. In $O$. D. vision had risen to $6 / 1 x$, and the field of vision for form had widened to nearly normal, except an area of blindness even for candle flame, which included almost the exact lower nasal quadrant. In the left eye the temporal field was nearly normal, but the entire nasal field was blind to candle flame. With $+3.00 \mathrm{~s}=+3.00 \mathrm{cy}$ ax $165^{\circ} \mathrm{V} .=6 / \mathrm{xii}$.

May, 1895, a month later: V. in O. S. same, but in O. D. V. had risen to $6 / x$ viii.

November, 1895, six months later: Vision in the right eye had slowly fallen again to $6 / \mathrm{xl}$ riii, with a concentric narrowing of the remaining field.

Oct. 10, 1898: The optic atrophy had stcadily progressed in the right eye to nearly total blindness, approximately three and a half years after the operation, but at no time had there been any increase of tension or other renewed signs of glaucoma.

The left eye, however, in which the cnset of the disease was more recent and the cupping of the nerve and atrophy less advanced, retained vision 6/xxiv, with no further change in the fields until the patient's death on Aug. 9, 1900. More than five years after the iridectomy.

There can be no reasonable doubt that had the iridectomy been performed at an earlier date this patient would have been spared blindness from atrophy in the right eye also. Had the operation been done before the serious impairment of the fields of vision in both ejes I am convinced that she would have enjoved throughout the remainder of her life approximately normal vision.

This conclusion would seem to find adequate corroboration in the history of the following patient, referred to me for operation by a colleague. Incidentally this case is introduced to represent a large group of patients operated on in private practice within the last ten years, seven of them within the last two years, in all of whom useful vision had been destroyed in one eye when first seen and the discase was already passing into the inflammatory stage, while in the other eye the disease was still in its incipiency. In all of them glancoma has been completely arrested in the second eve by operation, and at the present date without $e^{-}$ reption they enjoy approximately normal vision. The fate of the blind ere, furthermore, illustrates the danger of deferring operation even under the steady and judicious employment of a miotic.

CAse 6.-Chronic Glaueoma.

Patient.-Mrs. J., aged 60, consulted me Feb. 21, 1906. She had been using eserin under close observation for more than two years. Notwithstanding this, she had suffered exacerbations of dim sight from time to time, but no severe pain. Her vision in October, 1904 , was in $O$. D. $20 / \mathrm{xxx}$, in $\mathrm{O} . \mathrm{S} .20 / \mathrm{xv}$.

Examination.-When seen by me it had sunk in $O$. D. to $10 /$ ce. eccentric fixation. In O. S. to $20 / \mathrm{xxx}$. O. D. T. $=+2$, pupil dilated, A. C. shallow, media transparent, deep cupping, nerve atrophic, and marked pulse in both upper and lower temporal arteries. The sensibility of the cornea was impaired and only a small island remained in the temporal field near the fixation point. There was severe pain. $\mathrm{O}$. S. V. $=6 / \mathrm{ix}, \mathrm{T}$. $\mathrm{N}(+$ ?), ball had a rigid sclera, pupil reacted to light, $\mathrm{A}$. C. was shallow; there was a beginning cup at the lower border of the nerve, no retinal pulse, and no marked impairment of field.

Operation.-She was admitted to the Wills Fye Hospital and a broad peripheral iridectomy was performed on the right eye on Feb. 26, 1906. The convalescence was uneventful. The pain and tension were promptly relieved and she was discharged from the hospital on March 7 , with no improvement in the field.

Subsequent History.- She was readmitted to the hospital and on March 19, 1906, iridectomy was performed on the left eye. Convalescence was normal till March 21, when she had a sudden pain, probably from injury during sleep. The following morning the anterior chamber was filled with blocd. This was rapidly absorbed and recovery progressed without further in- cident. On May 18, 1906, two months after operation, with $+.25 \mathrm{~s}=+1.25 \mathrm{cy}$. ax. $170^{\circ} \mathrm{V} .=6 / \mathrm{v}$, and the field of vision was normal in all respects.

March 23, 1907, one year later: O. D. V. $=$ only q. p. l., optic nerve atrophic. O. S. +1.25 cy. ax. $170^{\circ} \mathrm{V} .=6 / \mathrm{v} . \mathrm{T} .=$ $\mathrm{N}$. in each eye. Eyes are white and free from pain.

CASE 7.-Simple Glaucoma.

Patient.- I. I., aged 4l, consulted me May 28, 1898, witlı simple glaucoma. At that time the right eye was apparently normal with $V .=6 / \mathrm{vi}$ and no restriction of the field. In the left eye vision was reduced to $6 / x v$ and a marked cut in the nasal field, the upper nasal quadrant being cut to almost fixation point. The anterior perforating vessels were full and tortuous. There was an arterial pulse in both upper and lower tempcral arteries and a well-marked glaucomatous cup.

operation.-Iridectomy was advised and performed on the left eye May 30, 1898. The operation was smooth and recovery without incident.

Subsequent History.-This patient was kept under observation at short intervals until September, 1899, at which tine there was a distinct cupping of the right optic nerve and a progressive narrowing of the field of vision, but worse in the - upper natsal quadrant. In a word, the eye was obviously pursuing the same history as the left had done before the operation. Vision in the left eye had risen to $6 / x$, and the field of vision was markedly improved in all directions except the upper nasal quadrant, which remained unchanged. Iridectomy was then adrised for the right eye also, but declined. Nothing more was hearl from this patient until during the preparation of this paper, when the rision in the left eye was found unchanged, but the right eye, on which she had rejected the advised operation, was totally blind.

This brief history of Case 7 is introduced to give the reverse of the picture as set forth in Case 6. Here the operation on the left eye had been. accepted early enough in its history to save the vision, whereas the right eye, which was not operated on and which was the better when first seen, had been allowed to take its corrse uninterruptedly to the end.

The case histories which have been introduced are selected simply for illustration and to demonstrate the claim which has been marle in the introrluctory remarks. vi\%, that the clinical history of glaucoma simplex, chronic or non-inflammatory glaucoma, when followed from the incipieney of the discase during long periods of time, demonstrates that the affection belongs, in its essential character, in the same category with glaucoma fulminans, or acute inflammatory glaucoma; that the latter violent manifestation of disease is in fact but the dénouement of the former. In a word, the symptom complex we have recognized as glancoma im. minens is a steadily advancing simple glaucoma, which, under the stress and strain of life, and the pathologic changes in the organism which come on and advarie between the forty-fifth and sixty-fifth years of age in large numbers of pcople, under favoring ocular conlitions culminate in the types of disease under discussion.

It is true that in a considerable number of individuals the culmination into acute inflammatory disease. for many reasons, may never come, but may, nevertheless, end in total blindness, beginning and ending as a purcly local manifestation of disense. But ard to the Insal affection some general dyscrasia-notably the rheumatic or gonty diathesis with the accompanying disease of the exenral vascular tree and the associated impairment of the genernl nutrition-and it is easy to conceive how the marticination of the ncular tissues, notally the uveal tract. in the general pathologic state. mav furnich local mechanical and nathologic conditions which sulminate in the inflammatory trnes of glaucoma and their striking symptoms-complex. Blindness already reached as the result of simple glaucoma does not, however, 
nccessarily avert the occurrence of acute glaucoma. Every surgeon must have found it necessary to do iridectomy or to remove the offending eye for the relief of pain in blind eyes with absolute glaucoma, it may have been many years after total loss of vision had been suffered.

The technic of iridectomy is important. 'lhere is probably no more difficult surgical procedure than iridectomy in the acute stage of inflammatory glaucoma. I am of the opinion that it should never be attempted except under profound general anesthesia. The hard eyeball, the steamy cornea, the shallow anterior chamber, the engorged, often inflamed iris, not infrequently form a group of conditions which make its correct and safe performance extremely difficult. The frequent failure to arrest the disease by the operation unfer these rifficult conditions is, I am sure, because it has been found impossible to carry out an ideal technic. These difficulties in the acute inflammatory stage furnish a strong reason for operation before the occurrence of glaucoma fulminans, not only for the purpose of averting this catastrophy in patients under observation, but for the sufficient reason that in the non-inflammatory stage of the disease the operation can be performed with case, precision and safety.

In no other operation on the eye is a faultless technic of more signal importance than in iridectomy for glaucoma if we hope to arrest the disease. This is always possible so long as we have an anterior chamber of approximately normal depth, a reacting iris and a patient quiet under general anesthesia.

I believe that, for a successful issue, the iridectomy should be peripheral, i. e., to the root of the iris, and that it should include onc-sixth of its circumference.

I very much prefer the triangular bent keratome, the blade of which is approximately an equilateral triangle, the base and the cutting sides being equal. The blade should be entered through the corneal limbus at a point as nearly as possible on the same plane with the anterior surface of the root of the iris and carried forward parallel with it until the base of the knife engages in the wound. The slow and deliberate withdrawal of the knife is important, as it allows the gradual escape of the aqueous, prevents the sudden impact of the lens against the cornea, and often aroids the prolapse of the iris into the wound. 'The iris forceps can then be made to seize the iris at a selected point near the rim of the pupil, when it should be gently but firmly drawn out and caryied strongly to one angle of the wound. The tension outward being steadily maintained, it can be severed at its base by successive snips with the scissors as the remaining uncut portion is carried toward the opposite angle of the wound. The severance being complete, the anterior chamber is apt to fill with blood; the angles of the wound, however, should be carefully freed from any entanglement of the pillars of the coloboma and the blood be allowed to escape by gentle but firm pressure made on the posterior lip of the wound by the flat side of an elastic tortoise shell spatula. If it is found impossible to free the anterior chamber of blood by this means no other effort should be made. 'The blood will usually be absorbed in from twelve to twenty-four hours and its presence is much less to be feared than the results of manipulation to secure its escape. It is probable that opacities of the capsule and lens cortex are more frequently caused by the efforts of the surgeon to free the anterior chamber from blood than from any direct injury to the lens by the point of the knife or by the forceps in grasping the iris.
In my experience the occurrence of cataract after iridectomy has been very rare except in cases in which the opacification of the lens had already begun before the operation. In one case of acute glaucoma with a very hard ball, a sudden escape of aqueous before the section was completed thrust the lens violently forward against the knife, rupturing the brittle anterior capsule and opacity followed, but in this case general anesthesia was prevented by the general condition of the patient.

\section{DISCUSSION}

ON PAPERS OF DRS. TEN NEY AND RISLEY.

Dr. Il. V. WÜrdemanN, Milwaukee, Wis., said that for the past year he had examined all cases of increased ocular tension that had come under his observation, and in a number of instances other members of the same family, by ocular transillumination, in bopes that this method would throw some light on the mechanism of glaucoma. Glaucoma is not a dis. ease per se; it is a condition, the most pronounced symptom of which is excessive intraocular pressure. Primary anterior glaucoma may be due $(a)$ to increased secretion; (b) to - sclerosis of the vessels. Secondary glaucoma may arise from previous iritic disease causing obstruction of the filtration apparatus, or due to closurc of the posterior chamber from iritic synechice. These conditions ( $a$ and $b$ ) are curable or alleviable by myotics or by the operations of iridectomy or sclerotomy.

Posterior glaucoma is due to obstruction $o$ : the vortical veins of the chorioid and diseased blood vessels, and is usually accompanied by general arteriosclerosis. Mixed types are due (a) to ocular tumors, which, from their growth and consequent intraocular pressure, produce obstruction of the anterior and posterior drainage apparatus; (b) so-called hemorrhagic glaucoma, usually due to subchorioidal hemorrhage which pro duces the same; for these two conditions enucleation is the only resort; (c) increased intraccular tension following injury to the lens which causes it to swell and press on the anterior filtration apparatus, obliterating the circumlental space and increasing the amount of albumin in the aqueous. Operations of iridectomy and removal of the lens are the usual recourse for this condition.

In the anterior types the diagnosis is assisted by transillumination. The diaphanoscope is best applied to the sclera at the outer canthus after application of 2 per cent. alypin or 5 per cent. cocain, although the light may be passed through the lids for superficial examination. The pupil is thereby lighted up and if the eye be looked at obliquely the opposite portion of the ciliary body will appear as a dark ring-the circumiental space as a clear ring at the root of the iris between the rounded margin of the lens and the ciliary processes. This is usually from 5 to $6 \mathrm{~mm}$. wide. If the lens diameter be increased or if it be further forward than normal, or if the-ciliary processes be thickened by congestion or if filled in by exudates, this space is encroached on and may be obliterated. The circumlental space is enlarged during accon modation.

Anatomic conditions, as a narrow circumlental spice, predis. pose toward increased ocular tension, and individuals of fam ilies who are prone to anterior glaucona will most of them be found to have a narrow circumlental space. Such cases do not have any increased tension except after the onset of conditions which cause glaucoma, but in them a small degree of swelling or congestion of the root of the iris or the ciliary processes tends to block up the space around the lens and thus interferes with drairase from the posterior to the anterior chamber and the filtration at the iridic angle. Traumatic cataract causes much the sane conditions.

In posterior glaucoma, unless the anterior chamber becomes smaller-and this is by no means always the case in the chronic, simple non-inflammatory type-diaphanoscopy is negative. In glaucoma produced by intraocular tumors the shadow of the tumor may be seen, and if the anterior chamber be affected the conditions above described will also be readily demon. strated. Thus, the lighting up of the eye by diaphanoscopy gives us some idea of the mechanism of glaucoma and the anatomic conditions that predispose to this affection. We 
cicarly sec that the anterior chamber is smaller, that the lens is further forward, and that the iridic angle and circumlental space are encroached on. Diaphanoscopy of the eye in glaucoma does not show anything new; it is, however, a valuable (c)rolyorative method of examination.

1)k. Jorn E. WEErs, New York City, said that, in considering the relation of chronic glaucoma to other forms of glaucoma with a view to its proper classification, it is necessary to inquire into the cause of glaucoma in general. This may be broadly stated to be a partial or complete blocking of the avenues for the eseape of fluid from the interior of the eye, an excessive flow of fluid into the eye, or both. Glaucoma is very appropriately divided into two great classes, namely, primary and secondary, which, to obtain a comprehensive knowledge of the subject most readily, should be studied in the reserve order, as Priestley-Smith has done.

P'rimary glaucoina, one form of which concerns us, presents, as we all know, a number of clinical pictures which differ widely, but if these various clinical forms of glaucoma are analyzed, it will be found that there is no sharp dividing line between them; one blends into the other. 'The form of glaucoma that is not subject to congestion may be termed noncongestive primary chronic glaucoma in contradistinction to the congestive forms which may or may not be chronic. This listinction must not be drawn too closely, as the non-congestive form of primary glaucoma, may, and often does, become congestive, passing into subacute and even into acute glaucoma.

The research and experimental work of Priestlev-Smith shows that the underlying eause of primary glaucoma in all of its phases is, in the vast nuajority of cases, obstruction to some degree of the filtration angle. In a few cases excessive secretion may overtax the normal avenues of escape and produce glaucoma.

No one who is informed doubts the efficacy of operative treatment in acute glaucoma. If we admit that chronic glaucoma and acute glaucoma are due to similar causes and that they differ in great part only in degree of severity, should we not expect that the same operative procedure that affords relief in the one would also afford relief in the other, provided that the procedure was applied at the proper time? The questions to be answered are: When is the proper time for opreration, and what operation or operations should be performed? The ehanges affecting the filtration angle, gradually causing the root of the iris to encroach on and to become adherent to sclera and cornea at the iris angle, and the atrophic influence on the nervous elements of the retina and the optic nerve, reduce the possibility of arresting the disease either by sufficiently opening the filtration angle or by favorabiy in. thencing the atrophy of nervous elements, in direct proportion to the duration of the disease. Dr. Week's experience is in full accord with that of Dr. Risley, namely, that the results have been very satisfactory in the cases that were operated on enrly and very unsatisfactory in the cases operated on late.

What operations shall be performed? To be of value, iridectomy should be performed before vision is much impaired and while there is still sufficient space between the iris, sclera and cornea at the iris angle to permit the making of an incision in the iris angle. It should effect the removal of a portion of iris at its place of attachment to the ciliary body so that 110 stump remains. About one-sixth of the iris should be removed. If the iris is already adherent to the periphery of the cornea, iridectomy is not of value.

Dr. Weeks uses a Graefe knife in making the incision, ex" $p$ t when the anterior chamber is fairly deep. The incision is made above; puncture and counterpuncture about $2 \mathrm{~mm}$. from the margin of the cornea, so made that the incision will be about $5 \mathrm{~mm}$. long internally. The Graefe knife is used beanse it can be made to enter the iris angle with more certainty than the keratome, especially when the anterior chamber is very shallow. If the anterior chamber is very shallow or the tension very high, a posterior scleral puncture is made. The iris usually bulges into the wound on completion of the section. It is seized near the pupillary margin, drawn toward the left, and the exposed iris radially incised at the extreme right. Traction is then made to separate the iris from its insertion for from 5 to 7 millimeters. The engaged part of the iris is then drawn to the right to free it from the wound and cut radially at the extreme left. The iris, if engaged, is then freed from the wound by means of the spatula.

Anterior sclerotomy is employed only as an adjuvant to iridectomy. Posterior sclerotomy is employed to facilitate the performance of iridectomy and in cases of simple chronic glaucoma which have become absolute to relieve tension. In the latter case the opening in the sclera is quite large and $T$ - or L-shaped. Section of the cervical sympathetic or removal of the superior ganglion of the cervical sympathetic is resorted to only as a last measure.

Dr. H. D. Bruns, New Orleans, said that about 40 per cent. of those who come to his clinic are negroes, and the negro, while not more often afiected by inflammatory glaucoma than the Caueasian, is more frequently the victim of non-inflammatory simple glaucoma. The negro is also liable to atrophy of the optic nerve, simple bluish-white atrophy with excavation, and it is sometimes difficult, if we do not insist on finding tension at all times, to decide whether we have slight excavation in an early case of chronic absolutely non-inflammatory glaucoma, or whether we have the beginning of atrophy with exavation. Dr. Bruns has come to rely very much on the shape of the field of vision. Those who do not practice in a country where negroes are numerous do not know, perbaps, that they never come in until they are reaily moribund, either as to their bodies or eyes. It is vain to talk of early operation, as they are never seen early. This has enabled him to satisfy himself beyond the peradventure of a doubt that when the disease is well established it is absolutely useless to operate. He agreed with those who say that it seems to accelerate the disease after it is fully established. Occasionally there is a chance to operate on the better eye. He has watched these cases for years and has never seen acute or subacute attacks in these negro patients.

He has been interested lately in a paper by LaGrange who believes that the incision in glaucoma facilitates the escape of fluid by the formation of a leaking scar and has recom. mended making the section so as to peak a little piece of sclera, then, by turning back the conjunctiva and clipping off this little peak, to enlarge the size of the cicatrix. LaGrange is a careful observer, and he writes of his experience in 20 cases, some of two years' standing, and finds that in this way he gets better results than with the simple incision.

1)r. J. I. Bonscri, Philadelphia, said that since the illustrious von Graefe described glaucoma we have learned little more ibout the disease. Dr. Borsch once asked de llecker what he thought glaucoma was due to, and he said that he did not know. If so great a master admits that he does not know, certainly a great many of the men who say they do can be mistaken.

Dr. Borsch has often compared the disease to a headache. He said that he considers it the symptom of an obscure condition of which we are as yet ignorant. Headache may be due to many things, as a brain tumor, intestinal irritation, or re fractive error. He does not believe that an iridectony does any more good than in sclerotomy (posterior and anterior combined) glaucoma. He did not think eutting the iris arrests the disease. He said that he had the honor of assisting de Wecker in the operation he did on Javal, who came to him with simple chronic glaucoma. He did a sclerotomy and maintained good rision for serenteen years. When he had another attack, de Wecker wanted to repeat the sclerotomy, but Javal wanted an iridectomy. He had the cervical ganglion removed, but the condition went on to complete blindnesss.

1)R. M. WIENER, St. Louis, sair that Vollert of Leipzig allows a picee of iris to be incarcerated in the wound. Dr. Ifenry L. Wolfner, many years ago, made the remark that he did not object if there was a slight prolapse of iris in the wound in iridectomy for glaucoma. He did not try to do it, but also did not try to replace it if it occurred. Three or four years ago he purposely started performing iridectomy by incarcerating an edge of iris in the wound, and claims to get permanent drainage in that way.

Prof. Carl Hess, Wuirzburg, Germany, said that for a patient with simple chronic glaucoma, one eye being blind and the other not, he tries irridectomy on the blind eye. If the result is encouraging he tells the patient that he is willing to try the operation on the good eye also, but that he can not 
promise him any good effect; that if nothing is done he will surely be blind, but that the operation may possibly result in some vision. He has frequently seen the iridectomy made without fault and vision lost after a short time, and it seemed often that it was lost still more quickly than in the eye in which no operation was done.

Dr. S. L. ZIEgrer, Philadelphia, agreed that an early operation is the best procedure. The suggestion of Dr. Wiener, in regard to the incarceration of the iris, reverts to some of the abandoned procedures of the early part of the last century. Incarceration of the iris would be very disastrous for most of us to contemplate on account of the possibility of sympathetic ophthalmia, for an incarcerated iris and a contracting wound may set up sympathetic trouble in the other eye at any time. If one wishes the wound to leak it would be preferable to turn a piece of the conjunctiva into the wound, but it would be better to make a posterior sclerotomy and then have a leaking of the posterior chamber, or rather, a governor to control the tension. He thought; therefore, it would be better to dress the iris back carefully, and see that there is nice healing of the wound with no inflammatory irritation afterward; otherwise there might still be another attack of glaucoma through plastic closure of the angle already freed. One of the objections to early iridectomy has been the possibility of cataract development afterward. Of course, it does develop in some of these cases, but generally it is the ordinary senile cataract, as glaucoma most frequently occurs in old patients. Another objection is that of varying astigmatism because of pressure on the corneal wound. It is, of course, possible that one may have every year a varying of the astigmatism requiring frequent refraction and change of glasses.

Posterior sclerotomy is an alternative operation that is often resorted to in certain circumstances. It is often done when the patient refuses the operation of iridectomy. IJe may be willing to risk the mider operation. Again, we may have such a shallow anterior chamber that it is dangerous to make the keratome incision. Of course, this is more easily performed with the narrow cataract knife; but even then there is some risk. A third class is that in which there is a possibility of hemorrhage into the eye. Dr. Ziegler said there is less danger of this accident after posterior sclerotomy than after iridectomy. He has performed posterior sclerotomy in a number of cases with good results. He has a patient in the Wills liye Hospital, on whom he did a cataract operation recently, who had a posterior sclerotomy five years ago for fulminating glancoma. He was able to reduce the tension at once, and, some weeks later, did iridectomy in both eyes. The iris of one eye was so rotten that it had to be taken out in small pieces. The other showed a very smooth coloboma. With proper glasses he has retained almost normal vision, lut requiring frequent refraction, as the astigmatism changed. Posterior seleiotomy is best performed ly plunging a Graefe knife into the eyeball midway between the extraocular museles and about $6 \mathrm{~mm}$. back of the limbus. Rotate the knife, press out a bead of vitreous, turn the knife at right angles and withdraw quickly, leaving a $T$-shaped incision.

Dr. J. O. McReynolds, Dallas, Texas, said that Leibrich of Paris said it was the practice of von Graefe to make the incision downward and inward instead of upward as we do now, and Dr. Liebrich was not sure even now that there is any particular value to be ascribed to that situation of the incision. Dr. Mackeynolds spoke of this in order to be enlightened. He sometimes had a case like this: A patient comes completely blind in one eye with glaucoma, and very much diminished vision in the other eye. The question is, if he did not operate, how long would the paticnt retain the vision; if he did operace, is there much danger of causing sudden loss of vision? In such cases he had sometimes made a compromise which seems to have worked satisfactorily, based on the idea that it is the peripheral character of the iridectomy as much as the extent of the iridectomy that is the valuable feature, and he was convinced that a more narrow iridectomy is a safer procedure than a very broad one. The traumatism is greater in a broad iridectomy. After a narrow iridectomy, there is left a sufficient amount of iris to hold the lens in better position, and there is more iris tissue for the myotic to operate on if it is to be used after the operation. He had had just as good results with the narrow iridectomy as with the broad one. There is less deformity and less dazzling with the narrow iridectomy. If the operation must be repeated it can be done, for many iridectomies can be made at different times if the necessity should develop.

Dr. HIrasr Woods, Baltimore, said that some incidental conditions which ought to receive attention are the age of the patient, condition of arteries, kidneys, etc., and state of the lens. He narrated the case of a woman, 77 years of age, who came to find why she was "sometimes unable to see." With slight myopic correction her distant vision in each eye was $20 / 30$. Hie could not get illumination with the ophthalmoscope, and a drop of euphthalmin ( 5 per cent.) was put in each eye and she was sent to the waiting room. In a half hour both pupils were dilated ad maximum, with increased tension in the right eye. Then he found opacities at the periphery in each lens, floating bodies in each vitreous, but the fundus in good shape. Special attention was paid to the arteries. There was no pain and a rough examination of the right field indicated contraction in the inferior nasal quadrant. Eserin was ordered. Two days elapsed before tension was normal in the right eye and the pupil was as small as that of the left. Central vision was again $20 / 30$, but the field was contracted to nearly 30 degrees in the quadrant indicated. This was in May, 1906. Eserin was used during the summer while he was abroad. In the autumn she saw Dr. Risley, who, finding no increased tension but a cloudy lens, ordered a weak solution of homatropin. Later she returned to him with increased tension. He found further contraction of the field, but this was the only symptom of chronic glaucoma except the increase of tension by a mydriatic. Dr. Risley ordered eserin. When Dr. Woods saw her again in November, the field was contracted on both sides of the lower half, with a tongue-like scotoma shooting in toward the fovea, and reaching within 20 degrees of the latter, from the inferior nasal field. Central vision was as recorded, there was no pain, and the lens condition was unchanged. There was no bending of the vessels at the disc margin. The general condition wats good. On the strength of Dr. Bull's observations, his own experience, and with Dr. Risley's approval, 1)r. Woods did an iridectomy. The result was rapid and complete clouding of the lens, and development, after a fortnight, of acute glaucomil. There have been several attacks since. He told Dr. Bull about the case, and asked if the age and opacity of the lens should have kept him out of it. The reply was: "It would have kept me." J)r. Woods said it would keep him out of it another time. There are definite operative risks in these cases. I'rol)ably, with the slow progress of the disease, as regards contral vision, at least, and no evidence of glaucoma in the left eye. a woman at the age of 77 would have preserved useful vision the balance of her life, in one if not in both eyes. Dr. Won:s was sure he did not puncture the capsule during operation, yet the operative traumatism seems to have caused rapid swelling ald opacification of the lens with subsequent acute giaucoma.

Prof. Carl Hess, Wiirzburg, Germany, said, conceming the extent of the iridectomy, that he has repeatedy made a sinall peripheral buttonbole and thas had good sucess, so that he considers the extent of the iridic excision of no importance; a small iridectomy does just as well as a large one. IIe referred only to the simple cases, one fre lilint ant the ofluer benting worse; but a much more difficult question arises when both eyes retain good central vision and only the visnal fields are contracted. Dr. Hess asked what American ophthinhologists do in these cases. Before he crossed the ocenn he saw a woman of 36 who had been operater on-an iridectomy for chronic glaucoma. In one eye the lens had been injured and a complete cataract had been afterward extracted. Whon ise saw her the anterior chamber was deep, the optic disc white, with excavation, but central vision nearly normal. In the other eye the lens was transparent, the fields a little smaller than normal, and normal central vision. He refused to operate as long as vision was nearly normal. He has ised eserin for weeks or months and often that is sufficient to keep the vision normal. In the case mentioned the attendant wished him to do the operation and insisted that every six months for some years past the field had been found to be smaller and 
smaller, but Dr. Hess declined to operate while the vision continued to be almost normal.

Dr. Joir A. Tenney, Boston, agreed with Dr. Würdemann's statement that there is posterior glaucoma. Intraocular tumors may close the circumlental zone; but Dr. Tenney was speaking of ordinary chronic glaucoma. Several years ago a certain patient had traumatic cataract in one eye. It was evidently a soft cataract, very white, and the iris was paralyzed so that only a slight rim remained. Two years ago, Dr. Tenney removed it by needling. Since his paper was sent in this patient came to him, and had hardly noticed that the rision had nearly gone out of that eje. Dr. Tenney noted the increased tension and suggested that withdrawal of the aqueous might help the vision. It did not have that effect. He tested the fluid and found it loaded with albumin. Here was a case of chronic glaucoma going on so insidiously that the patient hardly knew that it existed, and the aqueous was loaded with albumin. That confirmed Dr. Tenney's opinion that chronic glaucoma may be caused by closure of the filtration angle by an excessive amount or albumin in the anterior chamber.

DR. S. D. Rrsley, Philadelphia, said that he had never approached a subject, before this Section or elsewhere, with more perturbation than this one. He purposely avoided, in the paper, any allusion to the etiolosy of glaucoma, or to the reasons for doing what he had suggested, other than those pointed out in the clinical histories related. He declared that a careful reading of the text of the paper, which was written with much care and forethought, on a subject which has agitated his mind for many years, will show that every inquiry raised in the discussion is thoughtfully answered in the clinical pictures supplied. He started out primarily to give a careful analytical study of the 140 cases on which the paper was based. Such study was made, but the analyses were not given in the paper.

He has always used the bent keratome, the character of which is described in the papcr. He agreed with Dr. Bruns regarding the tendency of the colored race to chronic simple glancoma, but his experience does not agree with Dr. Bruns as to its never passing into the inflammatory type. He had repeatedly seen the chronic non-inflammatory glaucoma present in one eye and the inflammatory type of older date present in the other. In that respect he did not think that the colored race differs materially from the white. One of the contentions - in his paper is that these forms of the disease are one and that, if the patients live long enough, even if blindness has come to pass during che non-inflammatory stage of the disease, it will sooner or later pass into the congestive, more or less pronounced inflammatory type.

He had many times been compelled to enucleate eyos, long blind but painless, for a more or less sudden onset of acute fulminating glaucoma. He said that he appreciated very hishly the conservatism of 1)r. Hess' advice, and emphasized the necessity for the greatest conservatism in the mamegement of glaucoma simplex. A carcful readirg of the histories given in his paper, he said, would show that he had again and again to operate on one blind cye presenting a moderately congestive form of glaucoma which had, nevertheless, gone on for many months, in some cases for years, without inflammatory exirerbations, but which finally compelled the patients to seek relief from the intolerable pain of the final inflammatory stage, while the fellow-eve still presented the characteristic non. inflammatory type of the disease, with the contracting field of vision, doubtful tension and cupping of the nerve.

Removal of Piece of Glass from the Pericardium. - A robust young man was stabbed in the heart with a long, pointed piece of window olass. The threatening svmptoms of hemo-pneumothorax the next day compelled surgical interference, and Ortiz de la Torre found and successfully removed the pointed tip of the glass, which had broken off in the wound. It measured $11 / 2$ by $3 / 4$ inches, and was found in the pericardium, the tip implanted in the wall of the auricle, rising and falling with the latter. The pulse tracings and other details of the case and operation are given in the Siglo Medico, liv, page 338, 1907. At date of writing, a week later, the patient. was in good condition, pulse 86 , temperature normal and respiration tranquil. The wound was sutured without drainage.

\section{THE PREVENTIVE TREATMENT OF TRANS-} FERRED OPHTHALMITIS.

\section{(SO-CALLED SYMPATHETIC OPHTHALMIA.)*}

\author{
CHARLES A. OLIVER, A.M., M.D. \\ PHILADELPIIIA.
}

For many months I have been engaged in the collation of the histories of all of the recorded cases of every form of so-termed "sympathetic disease"1 that had been treated in the dispensary and indoor services of Wills Hospital in Philadelphia since its opening, a period embracing more than seventy years.

During these studies-in which I received excellent help from three of my personal assistants ${ }^{2}-\mathrm{I}$ soon realized that in spite of a vast yearly increase of the work done at the hospital and a broader and earlier recognition of the condition, there was a decided lessening in the number of cases, and a much less degree of fatality among those which had been treated than in former years. These findings seemed so important that I instantly chose the preventive phase of the disease as worthy to be the subject of this paper.

The many desultory, and at times uncertain, cases of the first thirty-five years' work of the hospital were grouped together, while the latter half of this portion of the hospital's work, which had been systematically arranged into annual groups, was divided into periods of time similar to those which I had used in a study of several thousand cases in which senile cataract was extracted.

Critical inquiry into the detailed histories of the cases elicited many points of value. For example, it was found ${ }^{3}$ that, in spite of a vast increase of the types of cases which are ordinarily supposed to be provocative of the condition (some 62 per cent.), the proportionate number of cases seen was actually reduced nearly 80 per cent. within the past ten years. This is a remarkable improvement and one which is worthy of special record, when it is considered how long the institution has cxisted, that it is situated in the midst of a large industrial and commercial center, that it is near to an immense mining territory and agricultural district, and has always been favorably known-reasons, which. for many years past. have keen the means of bringing from ten to fifteen thousand new eye cases annually to its doors.

Employing the title "preventive treatment" as it should be employed, i. e., to express both the indircet and the direct preventive measures for lessening the chances of occurrence of the disease, I here offer some of them in brief detail under their two respective headings.

*Read in the Section on Ophthalmology of the American Medi cal Association at the Fifty-eighth Annual Session, beld at At lantic City, June, 1907

1. As I have elsewhere stated, for several years past $I$ have taught my classes and private students that so-called "sympathetic irritation" and "sympathetic ophthalmia" are simply different stages of a condition which is preferably termed "transferred ophstages of a condition which is preferably termed "transferred ophthalmitis." I believe that the expression "sympathetic," as ordinarily understood in this connection, has no significance what-
ever, and I am certain that the term "irritation" is just as false; ever, and I am certain that the term "irritation" is just as false :
it must be conceded also that the word "ophthalmia" should not be applied to any form of inflammation of the interior of the eyeball. The word "transferred" is correct, no matter what the process may be, and the generic term "ophthalmitis" is both adequate and com prehensive.

2. Drs. S. Rush Ketcham, Albert J. Britt, and Ida Loulse Haverstick.

3. As noted in the "Discussion on Sympathetic Ophthalmia." before the 1906 (seventy-fourth) annual meeting of the British Medical Association, Toronto, Ontario. 